\title{
EFFECT OF PURDUE IMPROVED CROP STORAGE (PICS) BAGS ON THE
}

\section{QUALITY OF STORED BEANS (PHASEOLUSVULGARIS)}

\section{DOMINIQUE SAVIO NKUNDA}

Department of Biotechnology, INES Ruhengeri-Institute of Applied Science, Musanze, Rwanda

\begin{abstract}
Purdue Improved Crop Storage (PICS) bags are useful to stop grain pest proliferation. They are cheap, easy to use and they improve the sensory properties of grains. Samples of beans were stored for 2 months in PICS and PP bags, and then compared to bulk and true density, water absorption capacity, moisture content, total polyphenol, protein content, cooking time, and sensory analysis. While there was no significant difference $(p<0.05)$ of other tested parameters for the beans stored respectively in PICS and in PP bags the water absorption capacity (41.75\%) and the cooking time (207 min) of PICSstored beans were significantly higher than their counterparts stored in PPbags with respective values of $26.66 \%$ and 185 min. In the sensory test, the assessors identified the difference between the two samples $(\alpha>95 \%)$ in both raw and cooked states and preferred the PICS stored beans. It was therefore concluded that the praised benefits of PICS stored beans were due the protection against insects, improved organoleptic characteristics, but not to any positive effect on the cooking time. Further research is needed to deeply investigate the effect of beans hardening during storage in PICS bags.

KEYWORDS: Hard-To-Cook, PICS, Triangle Test \& Woven Polypropylene Bags
\end{abstract}

Received: Jan 16, 2018; Accepted: Feb 14, 2018; Published: Mar 05, 2018; Paper Id.: IJASRAPR20187

\section{INTRODUCTION}

Grain storage is a key challenge for legumes, small -scale growers (Baributsa et al, 2010) in Africa because of the risk of losses by bruchids. Some effective storage chemicals are available, but they are regularly misused by farmers and merchants. The Purdue Improved Crop Storage (PICS) bag was created by the Purdue University to address these problems.

Extension methods are conducted to disseminate the technology in West-Central Africa (Caroll and Fulton, 2008) and the results show that farmers are adopting the PICS bags (Ibro et al, 2014)because of they are proven higher and better quality grains for family consumption and their higher flexibility in marketing.

Mutungi et al (2014) stored dry mung beans and pigeon pea grains in PICS bags and woven polypropylene (PP) bags for 6 months. Some of the bags were artificially infested with cowpea bruchid Callosobruchus maculatus (F.) while others were not. In an additional trial, PP bags containing the grains were treated with Actellic Super Dust before being artificially infested. After six months of storage in PICS bags, the multiplication of C. maculatus was stopped and the initial damage level and the weight of grains had not changed. They concluded that PICS bags were an effective tool for preserving mung beans and pigeon peas against $C$. maculatus attack, and the performance were even superior to that of Actellic Super Dust.

The same satisfactory results were obtained by Baoua et al (2014) on maize naturally infested with Prostephanus truncatus Horn, Sitophilus zeamais Motschulsky, and Rhyzopertha dominica (F.). After 6.5 months of storage in PICS 
bags, there was 95-100\% insect mortality. Furthermore, Williams et al (2014) demonstrated that PICS bags were a viable management tool for preventing aflatoxin, accumulated in maize storage. William et al (2017) stored maize infested with Sitophilus zeamais (Motshulsky) for eight months in PICS bags and woven PP bags. They noticed that PICS bags were superior to woven PP bags in terms of grain quality specific metrics. A comparative research was conducted on shelled and unshelled groundnut naturally infested with Tribolium castaneum (Herbst), Corcyra cephalonica (Stainton) and Cryptolestes ferrugineus (Stephens) and stored in PICS bags and PP woven bags for 6.7 months (Baributsa et al, 2017). There was an increase of the pest population for both shelled and unshelled grains stored in woven PP bags in contrary to those stored in PICS bags.

Currently, the effects of these PICS bags on the physico-chemical quality of stored bean, especially on the development of the hard-to- cook phenomenon is unknown. This paper reports a research on the effect of PICS bags on some physico-chemicals and sensory characteristics of beans (Phaseolus vulgaris).

\section{MATERIALS AND METHODS}

\section{Collection and Preparation of Materials}

$25 \mathrm{~kg}$ of freshly harvested red kidney beans was purchased from a local farmer in Rukozo sector, Rulindo district, and transported to the Laboratory of Food Processing in the College of Science and Technology, University of Rwanda, Kigali. PICS bags and woven PP bags were purchased respectively from ECOPLAST Kigali and from the open market in Kigali. Woven PP bags are originally used for rice or maize flour packaging and are re-used for different home storage purposes. PICS bags are sold in two sizes, for 50 and $100 \mathrm{~kg}$ grain storage. The $100 \mathrm{~kg}$ grain storage bags were cut into small bags and well sealed to store $2 \mathrm{~kg}$ of grains. Fresh beans were tested, in 3 replicates, for physico-chemical characteristics including the bulk and true densities, the water absorption capacity, the moisture content, the hard-to-cook (HTC) phenomenon, the total polyphenol content, the protein content, and the sensory evaluation. The remaining beans were kept, one batch, by lots of $2 \mathrm{~kg}$ in the small PICS bags prepared as explained above, the other batch was kept in woven PP bags, for two months, in a dry place at room temperature (around $25^{\circ} \mathrm{C}$ ), and re-tested for the same characteristics as above.

\section{Measurement of Bulk Density}

The measurement of bulk density used Fasina method (2010) and consisted in filling a $250 \mathrm{ml}$ measuring cylinder with beans via a funnel and weighing on an analytical balance (Denver Instrument MXX-2001). The bulk density was obtained from the ratio of the measured mass of the sample to the volume of the container. Measurements were done in 3 replicates.

\section{Measurement of True Density}

The true density of the samples was measured using a $250 \mathrm{ml}$ measuring cylinder filled with beans as previously described for the bulk density. Water was poured into the cylinder to the top to fill the avoid between the grains. The volume of the required water was recorded. The true density was then computed as the percentage of the ratio of the bean mass over the difference between $250 \mathrm{ml}$ and the volume of the required water. Measurements were recorded in 3 replicates. 


\section{Measurement of Water Absorption Capacity}

Water absorption capacity of bean samples was determined using the method described by Nwosu (2010) with minor modification. A quantity of 100 grams of beans ( 3 replicates) was soaked in $400 \mathrm{~mL}$ of water in a beaker and allowed to stand at room temperature for 24 hours. The water was then drained and the beans dried on a towel paper and weighed. The water absorption capacity was calculated as the percentage of mass increase over the initial mass of the bean sample.

\section{Measurement of Moisture Content (MC)}

The MC was determined by the oven drying method of the AOAC (1999). The control or blends were oven dried (Memmert UFE-400, Memmert GmbH + Co KG,D-91126 Schwabach FRG, made in Germany) at $105^{\circ} \mathrm{C}$ for 3 hours to have constant weight. Thereafter, the MC was expressed as the percentage of the ratio of the differences in weight of control or blends before and after drying to their original weight used.

\section{Measurement of Total Polyphenol Content (TPC)}

The TPC was determined by spectrophotometry, with the Gallic acid as a standard, as described by Keskin-Šašić et al (2012). Briefly, $0.2 \mathrm{~g}$ of the sample was transferred in tubes containing $1.0 \mathrm{ml}$ of a $1 / 10$ dilution of Folin-Ciocalteu's reagent in the water. After waiting for $10 \mathrm{~min}, 0.8 \mathrm{ml}$ of a sodium carbonate solution $(7.5 \% \mathrm{w} / \mathrm{v})$ was added to the sample. The tubes were then allowed to stand at room temperature for $30 \mathrm{~min}$ before measuring absorbance at $743 \mathrm{~nm}$ (Beam Scanning UV/Visible Spectrophotometer M-501, manufactured by Camspec Ltd, 11 High Street, Sawston, Cambridge CB2 4BC UK, assembled in China by UNICOSH). The TPC was expressed as Gallic acid equivalents (GAE) in mg/100 $\mathrm{ml}$ of material. The concentration of polyphenols in the samples was derived from a standard curve of Gallic acid ranging from 0.2 to $4 \mathrm{mg} / \mathrm{L}$.

\section{Measurement of Protein Content}

The protein content was assessed using the Biuret test and a spectrophotometric measurement with a standard curve established at $540 \mathrm{~nm}$ with bovine serum albumin concentrations ranging from 0.0 to $0.35 \mathrm{mg} / \mathrm{mL}$ (Keppy and Allen, 2009; Janairo et al, 2011).

\section{Measurement of the Hard-to-Cook (HTC) Phenomenon}

A modified Mattson bean cooker with 13 metal rods calibrated to $126 \mathrm{~g}$ each was used. Thirteen bean grains were positioned in the bean cooker. The beans were cooked in distilled water to avoid the interference from foreign ions (water hardness). During cooking, the time was counted from when the water started boiling. Beans were fully immerged and the water level was maintained by addition of boiling distilled water.

The comparison was made between fresh beans and stored beans on one hand, and beans stored in PICS bags and woven PP bags on the other hand, by using the median cooking time of the 7th bean (CT7).

\section{Sensory Evaluation}

The triangle test was used to detect any difference in sensory properties in beans stored in PICS bags and woven PP bags. Three coded samples, two of which were identical, were simultaneously presented to each assessor who was asked to select the odd sample. Samples were presented an equal number of times in each of the two sets of three distinct permutations of order: $\mathrm{BAA}, \mathrm{AAB}, \mathrm{ABA}, \mathrm{ABB}, \mathrm{BBA}$ and $\mathrm{BAB}$, where $\mathrm{A}$ represented beans stored in woven PP bags and 
B the beans stored in PICS bags. The assessors were asked specific relevant question(s) referring to the difference and their confidence in their decision. "No-difference" replies were allowed. For no-difference replies, they were allocated randomly to each of the categories of replies. The difference tests were performed using the following pairs of samples: 1) Raw beans stored in PICS bags versus raw beans stored in woven PP bags; 2) Cooked beans stored in PICS bags versus cooked beans stored in woven PP bags. To check if assessors could significantly detect the difference between samples a statistics table of critical values for the paired comparison tests was used.

\section{RESULTS}

The experimental results are shown in table 1. After 2 month-storage, compared to the fresh beans, the bulk density and the true density decreased significantly $(\mathrm{p}<0.05)$ for both bags, the water absorption capacity increased significantly $(\mathrm{p}<0.01)$ for PICS bags only, no significant change of moisture content $(\mathrm{p}>0.05)$ was observed for both bags; the TPC content decreased significantly for both bags; the protein content decreased significantly (0.01) for woven PP bags only, The median cooking time (CT7) increased with storage for both bags.

During the sensory evaluation by the triangle test, 19 assessors out of 25 ( $\mathrm{p}<0.05)$ identified the odd sample and preferred the beans stored in PICS bags, for both raw and cooked beans..

Table 1: Results of Selected Quality Analyses of Beans Stored for 2 Months

\begin{tabular}{|l|c|c|c|}
\hline & $\begin{array}{c}\text { Fresh } \\
\text { Beans }\end{array}$ & $\begin{array}{c}\text { Beans Stored } \\
\text { in PICS Bags }\end{array}$ & $\begin{array}{c}\text { Beans Stored in } \\
\text { Woven PP Bags }\end{array}$ \\
\hline \multirow{2}{*}{ Bulk Density for bean samples (g/ml ) } & $\begin{array}{c}0.850 \\
+0.001\end{array}$ & $\begin{array}{c}0.815 \\
\pm 0.012\end{array}$ & $\begin{array}{c}0.821 \\
\pm 0.005\end{array}$ \\
\hline \multirow{2}{*}{ True Density for bean samples (g/ml ) } & $\begin{array}{c}2.352 \\
\pm 0.035\end{array}$ & $\begin{array}{c}2.240 \\
\pm 0.075\end{array}$ & $\begin{array}{c}2.054 \\
\pm 0.138\end{array}$ \\
\hline \multirow{2}{*}{ Water absorption capacity (\%) } & 22.50 & 41.75 & 26.66 \\
& \pm 2.32 & \pm 3.03 & \pm 2.88 \\
\hline \multirow{2}{*}{ Moisture content of bean samples (\%) } & 11.62 & 13.52 & 12.84 \\
& \pm 1.44 & \pm 0.02 & \pm 0.06 \\
\hline \multirow{2}{*}{ Total polyphenol content (mg/100mL) } & 0.0309 & 0.0156 & 0.0085 \\
& \pm 0.0056 & \pm 0.0038 & \pm 0.0021 \\
\hline \multirow{2}{*}{ Protein content (mg/L) } & 0.2371 & 0.2370 & 0.2340 \\
& \pm 0.0006 & \pm 0.0006 & \pm 0.0004 \\
\hline \multirow{2}{*}{ Median Cooking time CT7 (min) } & 136.00 & 207 & 185 \\
& \pm 10.53 & \pm 1 & \pm 3 \\
\hline
\end{tabular}

\section{DISCUSSIONS}

When comparing the performance the two storage bags, beans stored in PICS bags have significantly $(\mathrm{p}<0.01)$ a higher water absorption capacity than those stored in PP bags. It can be implied that the tightness of the PICS bags did not allow the moisture loss during storage unlike the woven PP bags.

The depletion of TPC, is significantly higher for PP bags $(\mathrm{p}<0.05)$ than PICS bags. The TPC is often associated with the antioxidant activity of foods (Bramorski, et al, 2010), which is a nutritional advantage of PICS bags.

After two month-storage it appears that beans stored in PP bags have better cooking quality $(\mathrm{p}<0.001)$ as measured by the Mattson bean cooker. This seems to be in contradiction with the observed values of water absorption capacities. This needs to be confirmed by further research. 
Finally, the triangle test showed that the use of the two bags result in different quality beans. Assessors preferred clearly $(\mathrm{p}<0.05)$ beans stored in PICS.

\section{CONCLUSIONS}

PICS bags have already demonstrated their performance in grain preservation against storage pests. This research adds the higher water absorption capacity, the retention of water, total polyphenols and proteins, and the better sensory properties to the array of use benefits of PICS bags in grain storage. A longer storage period is however needed to confirm the observed better cooking quality of PP bags compared to PICS bags.

\section{REFERENCES}

1. AOAC. (1999). Official Methods of Analysis. 15th Ed.

2. Baoua, I. B.; Amadou, L. ; Ousmane, B.; Baributsa,D.; Murdock, L. L. (2014). PICS bags for post-harvest storage of maize grain in West Africa. Journal of Stored Products Research (2014), http://dx.doi.org/10.1016/j.jspr.2014.03.001.

3. Baributsa, D; Baboua, I. B.; Bakoye, O. N.; Amadou,L.; Murdock,L. L. (2017). PICS bags safely store unshelled and shelled groundnuts in Niger. J of Stored Prod Res 72 (2017) 54-58.

4. Baributsa, D. J.; Lowenberg-DeBoer, L.; Murdock, L. L. and Moussa, B.(2010). Profitable chemical-free cowpea storage technology for smallholder farmers in Africa: opportunities and challenges. 10th International Working Conference on Stored Product Protection. Pp. 1046-1052.

5. Bramorski, A.; Cherem, A. R.; Marmentini, C. P.; Torresani, J. ; Mezadri, T. ; Costa, A. A. S.(2010). Total polyphenol content and antioxidant activity of commercial Noni (Morinda citrifolia L.) juice and its components. Braz. J. of Phar. Sc. Vol. 46, no 4.

6. Caroll, N. J.; Fulton, J. R. (2008). Extension Methods to Teach Hermetic Storage in West Central Africa. An ASABE Meeting Presentation. Paper Number: 084981.

7. Fasina, O. O. (2010). Measuring Grain and Legume Seed Density Using a Pycnometer and Envelope Density Analyzer. Am Soc of Agric \& Biol Engin ISSN 2151-0032. Vol. 53(4): 1223-1227.

8. Ibro,G.; Sorgho, M. C.; Idris, A. A.; Moussa, B.; Baributsa, D.; Lowenberg-DeBoer, J. (2014). Adoption of cowpea hermetic storage by women in Nigeria, Niger and Burkina Faso. J of Stored Prod Res.

9. Janairo, G.; Sy, M,L.; Yap, L.; Llanos-Lazaro;N. L.; Robles, J. (2011). Determination of the Sensitivity Range of Biuret Test for Undergraduate Biochemistry Experiments. e -J of Sc \& Tech (5), 6, 2011.

10. Keskin-Šašić, I.; Tahirović, I.; Topčagić, A.; Klepo, L.; Salihović, M.; Ibragić, S.; Toromanović, J.; Ajanović, A.; Velispahić, E.;Berrios, J. D.(2012). Total Phenolic Content and Antioxidant Capacity of Fruit Juices. Bull of the Chem \& and Technol $39: 25-28$

11. Govindaraj K \& Jancirani P, Effect of Pruning on Cocoa (Theobroma Cacao L) on Morphological, Flowering and Yield and Quality of Cocoa Beans, International Journal of Agricultural Science and Research (IJASR), Volume 7, Issue 6, November December 2017, pp. 113-118

12. Keppy, N. K.; Allen, M. W. (2009). The Biuret Method for the Determination of Total Protein Using an Evolution Array 8Position Cell Changer. Thermo Fisher Scientific, Madison, WI, USA. 
13. Mutungi C. M.; Affognon,H; Njoroge, A. W.; Baributsa, D.; Murdock, L. L. (2014). Storage ofmung bean (Vigna radiata [L.]Wilczek) and pigeonpea grains (Cajanus cajan [L.]Millsp) in hermetic triple-layer bags stops losses caused by Callosobruchus maculatus (F.) (Coleoptera: Bruchidae), Journal of Stored ProductsResearch (2014), http://dx.doi.org/10.1016/j.jspr.2014.03.004.

14. Nwosu, J. N. (2010). The Effects of processing on the Functional Properties of 'Oze' (Bosqueia angolensis) Seeds. Pak J of Nutr 9 (8): 781-786.

15. Williams, S. B.; Baributsa, D ; Woloshuk,C. (2014). Assessing Purdue Improved Crop Storage (PICS) bags to mitigate fungal growth and aflatoxin contamination. J of Stored Prod Res 59 (2014) 190-196.

16. Williams, S. B.; Murdock,L. L.;Baributsa, D. (2017). Storage of Maize in Purdue Improved Crop Storage (PICS) Bags. PLoS ONE 12(1): e0168624. doi:10.1371/journal.pone.0168624. 